Rabaska

Revue d'ethnologie de l'Amérique française

MATHIEU, FrançoIs. Les Cloches d'église du Québec. Sujets de

culture. Québec, Septentrion, 2010, 212 p. ISBN

978-2-89448-605-4

\title{
Julie-Anne Côté
}

Volume 11, 2013

URI : https://id.erudit.org/iderudit/1018548ar

DOI : https://doi.org/10.7202/1018548ar

Aller au sommaire du numéro

Éditeur(s)

Société québécoise d'ethnologie

ISSN

1703-7433 (imprimé)

1916-7350 (numérique)

Découvrir la revue

Citer ce compte rendu

Côté, J.-A. (2013). Compte rendu de [MATHIEU, FRANÇOIs. Les Cloches d'église

du Québec. Sujets de culture. Québec, Septentrion, 2010, 212 p. ISBN

978-2-89448-605-4]. Rabaska, 11, 243-245. https://doi.org/10.7202/1018548ar

Ce document est protégé par la loi sur le droit d'auteur. L'utilisation des services d'Érudit (y compris la reproduction) est assujettie à sa politique d'utilisation que vous pouvez consulter en ligne.

https://apropos.erudit.org/fr/usagers/politique-dutilisation/
Cet article est diffusé et préservé par Érudit.

Érudit est un consortium interuniversitaire sans but lucratif composé de l’Université de Montréal, l'Université Laval et l'Université du Québec à Montréal. Il a pour mission la promotion et la valorisation de la recherche. https://www.erudit.org/fr/ 
scientifique. L'ouvrage éclaire à lui seul un vaste pan de la culture populaire au Québec en abordant des questions universelles, à partir de croyances et de pratiques spécifiques, dont témoignent des personnes qui n'ont guère laissé d'autres traces de leur vécu. Cette somme d'expériences vécues dans une période de transition dans l'univers de la naissance, brillamment synthétisées et explicitées par Suzanne Marchand, nous montre, plus largement, comment s'opère le changement social. Cet ouvrage majeur, de lecture aisée, instructive et même fascinante, deviendra assurément un incontournable sur le sujet.

Johanne Daigle

Université Laval

Mathieu, François. Les Cloches d'église du Québec. Sujets de culture. Québec, Septentrion, 2010, 212 p. ISBN 978-2-89448-605-4.

L'auteur François Mathieu, bachelier en philosophie et en arts plastiques de l'Université Laval, détient aussi une maîtrise en études québécoises de l'Université du Québec à Trois-Rivières, dont le livre Les Cloches d'église du Québec. Sujets de culture en constitue le mémoire. À travers l'histoire campanaire du Québec, l'auteur met en lumière le potentiel expressif et symbolique des cloches d'église de même que leur valeur matérielle et identitaire, comme patrimoine à préserver et à mettre en valeur. La recherche des plus pertinentes menée par l'auteur vient enrichir la documentation québécoise dans le domaine plus vaste du patrimoine religieux du Québec. Le bilan fort intéressant que nous offre l'auteur est accessible à tous. Le livre se subdivise en quatre chapitres, précédés d'un avant-propos et d'une brève introduction.

La première partie de l'ouvrage esquisse un portrait historique de la campanologie tant européenne que québécoise, des fondeurs itinérants de la Nouvelle-France aux grandes entreprises de France et d'Angleterre. Ce chapitre souligne la valeur identitaire et le potentiel symbolique de la cloche. Comme le précise l'auteur, « ce qui autrefois était qualifié d'identitaire parce qu'il était religieux pourrait être vu comme identitaire en tant que culturel et historique » (p. 26). Pour lui, la cloche est un acteur important de l'histoire civile et politique d'un pays et, à ce titre, elle a un rôle culturel à jouer. Cette première partie propose donc une réflexion sur la cloche comme sujet de culture.

La deuxième partie présente la cloche dans ses aspects matériels et immatériels, à la fois témoin matériel du patrimoine, en tant qu'objet d'artisan et instrument de musique, et témoin du patrimoine immatériel à travers la pratique d'un savoir-faire. La cloche y est montrée comme un objet singulier, 
marqué au nom de ses donateurs ou de ses protecteurs, de styles diversifiés et aux attributs sonores uniques. Dans cette description, riche en histoire et en anecdotes, la cloche devient un symbole identitaire, lié tant à l'histoire intime de chacun qu'à la culture commune. En effet, la cloche se démarque en tant que repère historique des localités, dans la mesure où elle participe à de nombreux pans de l'activité humaine, accompagnant, par exemple, les événements de l'histoire locale comme les incendies, les baptêmes, les mariages et les mortalités. L'auteur souligne aussi l'importance du savoir-faire et de la maitrise technique dans la fabrication, l'installation et l'utilisation des cloches. Il introduit ainsi un aspect essentiel du patrimoine de la cloche que l'on pourrait qualifier d'immatériel, en lien avec la définition du patrimoine culturel immatériel de l'UNESCO. Dans cette partie, la cloche se révèle donc un objet-témoin signifiant du patrimoine culturel québécois.

La troisième partie est consacrée au patrimoine campanaire québécois. L'auteur y propose une sélection de trésors campanaires québécois, avec des critères de validation en fonction de la variété des objets, des usages et des mises en valeur passées et contemporaines. Il s'appuie sur des exemples concrets tirés d'archives paroissiales, de témoignages d'informateurs et des auteurs spécialisés en campanologie. Cette partie aborde aussi la pratique du change ringing ou sonnerie à permutation, dont des cloches d'église au Québec ont fait un usage particulier. Cette sonnerie, une activité artistique et collective à connotation identitaire et culturelle, mérite de se perpétuer pour l'auteur car c'est aussi un savoir-faire qui « passe par ceux qui font entendre ces cloches et qui donnent du sens à leur présence » (p. 164). Les exemples apportés dans cette partie, présentent donc les cloches comme garantes d'un patrimoine à préserver et à mettre en valeur.

Enfin, la quatrième partie se penche sur les modes de mise en valeur du patrimoine campanaire. L'auteur identifie certains vecteurs garants de pérennité et propose quelques démarches de mise en valeur. Entre autres, il mentionne l'importance d'une démarche de reconnaissance officielle pour les cloches, tel le statut de biens culturels par la Commission des biens culturels, comme c'est le cas de la cloche de Saint-Denis pour la cause patriote. Il souligne aussi la part importante prise par des artistes, tant en littérature, en musique qu'en arts visuels, dont les pratiques artistiques témoignent dans le présent, des démarches de mise en valeur du patrimoine campanaire. Pour l'auteur, la pérennité repose sur des usages mixtes conduisant vers de nouvelles pratiques plus expérimentales. Il donne en exemple le concert de musique contemporaine intitulé La Symphonie du millénaire présenté à l'Oratoire Saint-Joseph à Montréal sous la direction de Walter Boudreau ainsi que différentes expositions en arts visuels. Cette dernière partie laisse 
donc entrevoir de nouvelles avenues pour la mise en valeur du patrimoine campanaire.

Les Cloches d'église du Québec. Sujets de culture présente un intéressant bilan de la campanologie québécoise. La recherche menée par l'auteur est exhaustive, pertinente et abondamment illustrée. Toutefois, il aurait gagné à introduire davantage de références scientifiques ; par exemple, l'analyse aurait pu être soutenue par des références en ce qui a trait à la question du patrimoine culturel immatériel conduite par l'UNESCO. De plus, certaines sources bibliographiques sont citées d'après Wikipedia, qui n'est pas une source scientifique fiable. L'ouvrage n'en demeure pas moins un témoignage essentiel sur le patrimoine matériel et immatériel des cloches d'église. Certes, un important travail muséologique reste à faire pour la préservation et la mise en valeur de ce patrimoine. À ce titre, l'auteur fait référence au modèle d'économusée qui rend justice aux savoir-faire et à leur actualisation, un modèle pertinent pour préserver un patrimoine matériel et immatériel tel que le patrimoine campanaire. Les cloches renferment un riche potentiel en matière de repères culturels « conjugués au passé aussi bien qu'au présent et à l'avenir » (p. 193) qu'il importe de mettre en valeur.

Julie-Anne Côté Université du Québec à Montréal

Pascal, Jani. Contes populaires du Canada français. Montréal, Planète rebelle, « Mémoires », 2011, 229 p. + 1 DC [disque compact]. ISBN 9782-923735-26-9.

Pour ceux de mon âge, le nom de Jani Pascal évoque aussitôt Marie Quat' Poches, rôle qu'elle interprétait dans la Boîte à surprise, émission culte qui a marqué toute une génération d'enfants québécois. La fin de la série télévisuelle n'a pas sonné le glas de la carrière de Jani Pascal. Bien au contraire. Sa feuille de route est étoffée, comme en témoigne le rabat de la première de couverture. De comédienne, elle s'est faite naturellement conteuse et a participé à de nombreux festivals de contes, dont celui, inaugural si ma mémoire est fidèle, qui s'est tenu à Pointe-à-Callière : le Festival interculturel du conte. C'est à cette occasion que j'ai eu le plaisir de la rencontrer et d'échanger sur le conte.

D'elle, on connaît Contes à raconter et à écouter qui datent de 1988, et Contes à rire et à dire publiés en 1994. Avec Contes populaires du Canada français, Jani Pascal fait son entrée chez Planète rebelle, maison d'édition novatrice fondée par André Lemelin, qui se consacre à la publication de 